\title{
Sociodemographic And Reproductive Characteristics of Gynecological Cancer Patients Attending A Tertiary Care Hospital, Andhra Pradesh.
}

\author{
Dr.G.Venkata Lakshmi ${ }^{1}$, Dr.A.Krishna Veni ${ }^{2}$ \\ ${ }^{I}$ Assistant Professor, Department Of Community Medicine, RIMS Medical College, Srikakulam, Andhra \\ Pradesh \\ ${ }^{2}$ Professor \& HOD, Department Of Community Medicine, RIMS Medical College, Srikakulam, Andhra Pradesh
}

\begin{abstract}
Background: Gynecological malignancy is an important public health issue in the developing World and they include cancers of the ovary, cervix, body of the uterus, vulva \& vagina and also gestational trophoblastic neoplasia (GTN).Over the years, irrespective of social class, the number of gynecological cancers is increasing, with more cases at the younger age in India. Cervical malignancy is the most common among gynecological malignancies and WHO estimates that the contribution of cervical cancer to adult female death is 35\%. It has been reported in earlier literature that in developing countries like India, poor knowledge about these cancers and health care seeking behavior of the patients add to the burden of this disease significantly.

Objectives: 1) To study the socio-demographic profile of the study population.

2) To study the reproductive characteristics of the study population.

Methodology: A hospital based descriptive study was conducted for a period of 4 months. All the women diagnosed with gynecological cancers attending the radiotherapy unit for treatment during the study period were included.The data was collected by personal interview after taking an informed consent. Study tools included a pretested semi structured questionnaire.Study variables include age, age at menarche, age at marriage, age at first child birth, parity, menstrual hygiene etc. Data was analyzed using SPSS and relevant statistical tests were applied.

Results: A total of 183 gynecological cancer patients were included in the study. Majority (73.8\%) were cancer cervix patients, followed by cancer of the ovary (10.9\%) and cancer uterus (9.8\%). The age of the study population ranged from 18-80 years with majority in the fourth decade of life and the mean age of study population was 48.22 years. The mean per capita monthly income was Rs. 1332.5. All had early marriage and the mean age at first child birth was 16.49 years; majority (67.8\%) followed unhygienic menstrual practices.

Conclusions: Women in 40 's were most commonly affected and cervical malignancy has been identified as the most common gynecological malignancy.
\end{abstract}

Keywords: Cancer, Cancer Cervix, Cancer Ovary, Cancer Uterus, Cancer Vulva, GTN, Gynecological malignancies.

\section{Introduction}

Of the 10 million new cases of cancer diagnosed every year, over half of them are from the developing World. Cancer has become one of the ten leading causes of death in India and it was estimated that nearly 2 to 2.5 million cancer cases exist at any given point of time. Over 8-9 lakh new cases and 4 lakh deaths occur annually due to cancer. ${ }^{[1]}$ Cancers that affect primarily women are a special subset of health inequity, as many women in developing countries lack access to screening and treatment as a consequence of discriminatory beliefs and practices. Breast and cervical cancer were the commonest cancers among females and accounted for almost 1 million of the close to 6 million cancer cases that estimated to have occurred in developing countries in $2002 .^{[2]}$

Gynecological malignancy is an important public health issue in the developing World and they include cancers of the ovary, cervix, body of the uterus, vulva \& vagina and also gestational trophoblastic neoplasia (GTN).The major concerns in this regard are lack of cancer awareness in the community, uncertain epidemiology, variable pathology and lack of proper screening facilities ${ }^{[3]}$. Over the years, irrespective of social class, the number of gynecological cancers is increasing, with more cases at the younger age in India ${ }^{[4]}$ Cervical malignancy is the most common among gynecological malignancies and WHO estimates that the contribution of cervical cancer to adult female death is $35 \% .{ }^{[5]}$ According to data from population based registries under the National Cancer Registry Program in India, about 50-60\% of all cancers among women in India are related mainly to the four organs; cervix uteri, breast, corpus uteri, and ovaries. More than 70,000 new cases of cervix uteri, $3-8 \%$ of ovarian, $0.5-4.8 \%$ of corpus uteri, $1-3 \%$ of vulvar and gestational trophoblastic tumors are reported in India every year. In addition, nearly 75,000 Indian women die annually from cervical cancer disease $(58 \%) .{ }^{[6]}$ Women's low literacy level, cultural and religious factors, competing health needs, discriminatory 
feeding patterns, limited resources, poorly developed health care services, and limited information on cancer prevention are contributing to the increased burden of the gynecological cancers. Over $70 \%$ of the women report for diagnostic and treatment services at an advanced stage of disease, resulting in poor survival and high mortality rates ${ }^{[7] .}$ Delayed presentation of the cases always results in poor outcome, which could be averted by early detection of these cancers and prompt institution of treatment. It has been reported in earlier literature that in developing countries like India, poor knowledge about these cancers and health care seeking behavior of the patients add to the burden of this disease significantly

India's National Cancer Control Program emphasizes the importance of early detection and treatment but there is no organized screening program and the majority of Indian women lack both awareness about the disease and access to prevention and treatment facilities. Although cancer screening programs are presently available in all the regional cancer centers and comprehensive cancer care specialty hospitals, which include Pap smears, as well as colposcopy, it is restricted to limited population coverage ${ }^{[7]}$ The objectives of the present study are

1) To study the socio-demographic profile of women with gynecological malignancies attending a tertiary care hospital.

2) To study the reproductive characteristics of the study population.

2.1 Study Design: A Hospital based descriptive study.

\section{Methodology}

2.2 Study Setting: Radiotherapy department of King George Hospital, Visakhapatnam., Andhra Pradesh. King George Hospital is a 1052 bedded tertiary care teaching hospital. The radiotherapy department is the unit that provides chemotherapy and radiotherapy treatment to all the histo-pathologically confirmed cases of all cancer patients attending the department from north Coastal districts of Andhra Pradesh.

2.3 Study Population: Gynecological cancer patients attending the radiotherapy unit for treatment were included.

2.4 Sample Size: All the women with gynecological cancers attending the radiotherapy unit during the period of four months that is from April to July 2014 were included in the study.

2.5 Inclusion Criteria: All women with gynecological cancers who were attending the Radiotherapy unit for treatment and were willing to participate were included in the study.

Permission was taken from the Head of the Department of Radiotherapy to carry out the study. The patients were approached and explained the purpose of the study in their language. After obtaining informed consent, pre tested questionnaire was administered and information was recorded.

2.6 Study Tools: A pre-designed and pre- tested schedule, patient record books.

2.7 Study Variables: Study Variables include age, education status, occupation, economic status, age at menarche, age at marriage, age at first child birth, parity, menstrual hygiene etc.

2.8 Data Analysis: Data was analysed using SPSS and relevant statistical tests were applied.

\section{Results}

A total of 183 gynecological cancer patients that include Cancer of the cervix, Cancer of the uterus, Cancer of the ovary, Cancer of the vulva and GTN were studied.

In our study, majority $(73.8 \%)$ were cancer cervix patients, followed by cancer of the ovary $(10.9 \%)$ and cancer uterus $(9.8 \%)$. About $3.9 \%$ were cancer vulva patients and three were gestational trophoblastic neoplasia patients. Majority of the study population ( $87.4 \%$ ) were in the advanced stage of the disease at the time of diagnosis, i.e., $55.2 \%$ were in the third stage of the disease and $27.9 \%$ were in the fourth stage of the disease.

The age of the study population ranged from 18-80 years in our study. Majority were in the age group of $41-45$ years $(22.4 \%)$ followed by $36-40$ years $(15.8 \%)$. There were 16 patients less than 30 years of age. The mean age of study population was 48.22 years (SD- 12.29).

Table 3.1: Cancer wise distribution of Range $\&$ Mean age of the study population

\begin{tabular}{|l|l|l|}
\hline Type of cancer & Range in years & Mean age \\
\hline Cancer cervix & $27-75$ & 47.09 \\
\hline Cancer ovary & $18-70$ & 47.1 \\
\hline
\end{tabular}




\begin{tabular}{|l|l|l|}
\hline Cancer uterus & $59-80$ & 65.72 \\
\hline Cancer vulva & $28-65$ & 39.86 \\
\hline GTN & $19-24$ & 21.00 \\
\hline Total & $\mathbf{1 8 - 8 0}$ & $\mathbf{4 8 . 2 2}$ \\
\hline
\end{tabular}

The mean age of uterine cancer patients was 65.72 years with a range of 59-80 years which was two decades later than the mean age of all the gynecological cancers.

The difference between mean ages of various cancers was found to be statistically significant $p<0.05$ (ANOVA $\mathrm{F}=19.625)$

In our study, nearly $2 / 3$ rds $(60 \%)$ were illiterates, while $17 \%$ had primary school education, $10 \%$ had high school education and 6 were graduates .

Nearly half $(49.2 \%)$ of the study population belong to the upper lower class (IV) of modified B.G.Prasad's Classification for economic status. About $18.6 \%$ belong to Lower Middle class and $6 \%$ belong to Upper middle class. The range of the per capita monthly income was Rs. 200 to Rs.5000.

\section{Reproductive Characteristics Of The Study Population}

The age at menarche of total population ranged from 11-15 years with mean age of 12.59 years. The mean age of menarche was least among cancer uterus patients (11.56 years) as compared to other cancers. Mean age at menarche of cancer cervix patients was 12.67 years and 13.6 years for GTN patients

Table 3.2: Cancer wise distribution of study population according to menstrual history

\begin{tabular}{|c|c|c|c|c|c|c|}
\hline $\begin{array}{l}\text { Menstrual } \\
\text { history }\end{array}$ & $\begin{array}{c}\text { Cancer } \\
\text { cervix } \\
\text { n }\end{array}$ & $\begin{array}{l}\text { Cancer ovary } \\
\mathrm{N}\end{array}$ & $\begin{array}{l}\text { Cancer } \\
\text { uterus } \\
\mathbf{N} \\
\end{array}$ & $\begin{array}{c}\text { Cancer } \\
\text { Vulva } \\
\mathbf{N}\end{array}$ & $\begin{array}{r}\text { GTN } \\
\mathbf{N}\end{array}$ & $\begin{array}{c}\text { Total } \\
\text { n } \\
\end{array}$ \\
\hline Regular & $\begin{array}{l}121 \\
(89.6 \%)\end{array}$ & $\begin{array}{c}7 \\
(35 \%)\end{array}$ & $\begin{array}{c}10 \\
(55.6 \%)\end{array}$ & $\begin{array}{c}5 \\
(71.4 \%)\end{array}$ & $\begin{array}{c}2 \\
(66.7 \%)\end{array}$ & $\begin{array}{l}145 \\
(79.2 \%)\end{array}$ \\
\hline Irregular & $\begin{array}{l}14 \\
(10.4 \%)\end{array}$ & $\begin{array}{c}13 \\
(65 \%) \\
\end{array}$ & $\begin{array}{c}8 \\
(44.4 \%)\end{array}$ & $\begin{array}{c}2 \\
(28.6 \%)\end{array}$ & $\begin{array}{c}1 \\
(33.3 \%)\end{array}$ & $\begin{array}{l}38 \\
(20.8 \%)\end{array}$ \\
\hline Total & $\begin{array}{l}135 \\
(100 \%)\end{array}$ & $\begin{array}{c}20 \\
(100 \%)\end{array}$ & $\begin{array}{c}18 \\
(100 \%)\end{array}$ & $\begin{array}{c}7 \\
(100 \%)\end{array}$ & $\begin{array}{c}3 \\
(100 \%)\end{array}$ & $\begin{array}{l}183 \\
(100 \%)\end{array}$ \\
\hline
\end{tabular}

Majority had history of regular menstrual periods except ovarian cancer patients of whom $65 \%$ had irregular periods which was found to be statistically significant, $\mathrm{p}<0.05\left(X^{2}\right.$ value 39.33 , df 4$)$

Majority of the study population $(67.8 \%)$ followed unhygienic menstrual practices like using of reused cloth or not bathing daily during menstruation.

The proportion of patients practicing unhygienic menstrual practices, was high among cancer cervix (73.3\%) patients followed by cancer uterus $(61.1 \%)$. All the 7 vulvar cancer patients gave history of following unhygienic menstrual practices. This difference was found to be statistically significant $\mathrm{p}<0.05\left(X^{2}\right.$ value 21.745 , df 4)

Table 3.3: Cancer wise distribution of mean age at marriage and mean age at first child birth of the study population $(n=181)$

\begin{tabular}{|l|l|l|}
\hline Type of cancer & $\begin{array}{l}\text { Mean age at marriage in } \\
\text { years }\end{array}$ & $\begin{array}{l}\text { Mean age at first child } \\
\text { birth in years }\end{array}$ \\
\hline Cancer cervix $(\mathrm{n}=134)$ & 14.77 & 16.28 \\
\hline Cancer ovary $(\mathrm{n}=19)$ & 16.21 & 17.80 \\
\hline Cancer uterus(n=18) & 14.39 & 16.56 \\
\hline Cancer vulva(n=7) & 15.57 & 17.00 \\
\hline GTN $\quad(\mathrm{n}=3)$ & 17.33 & - \\
\hline Total & $\mathbf{1 4 . 9 6}$ & $\mathbf{1 6 . 4 9}$ \\
\hline
\end{tabular}

The age at marriage of study population ranged from10-19 years with mean age of 14.96 years. It was least among cancer uterus and cancer cervix as compared to other gynecological malignancies. This difference of age at marriage among the gynecological malignancies was found to be statistically significant $\mathrm{p}<0.05$ (ANOVA, $\mathrm{F}=5.670$ ).

In our study, majority of the study population had more than 2 children (75.7\%) among whom 20 patients had 6 children and 9 had 7 children. 7 women were nulliparous of whom 4 were carcinoma ovary and 3 were GTN patients. Multiparity (>3) was more commonly seen among Cancer Cervix patients (85\%), Cancer Uterus (73\%) and Cancer Vulva patients (71\%) as compared to other gynecological cancers. 
Nearly half (91/183) attained menopause and the mean age at menopause was 47.44 years. The mean age at menopause among uterine cancer patients was 48.31 years which was higher than the mean age of all gynecological cancers.

Table 3.4: Cancer wise distribution of study population according to the reproductive risk factors for gynecological cancers

\begin{tabular}{|c|c|c|c|c|c|}
\hline $\begin{array}{l}\text { Reproductive } \\
\text { characteristics }\end{array}$ & $\begin{array}{l}\text { Cervical } \\
\text { cancer } \\
\mathrm{n}=135\end{array}$ & $\begin{array}{l}\text { Ovarian } \\
\text { cancer } \\
n=20\end{array}$ & $\begin{array}{l}\text { Uterine } \\
\text { cancer } \\
\mathrm{n}=18\end{array}$ & $\begin{array}{l}\text { Vulvar } \\
\text { cancer } \\
\mathrm{n}=7\end{array}$ & $\begin{array}{l}\text { GTN } \\
n=3\end{array}$ \\
\hline $\begin{array}{r}\text { Menstrual History } \\
\text { Irregular }\end{array}$ & $10.4 \%$ & $65 \%$ & $44.4 \%$ & $28.6 \%$ & $33.3 \%$ \\
\hline \multicolumn{6}{|l|}{ Menstrual hygiene } \\
\hline Unhygienic & $67.8 \%$ & $35 \%$ & $61.1 \%$ & $100 \%$ & 0 \\
\hline \multicolumn{6}{|l|}{ Parity } \\
\hline $\begin{array}{l}\text { Nulliparous } \\
\text { Multiparous }\end{array}$ & $\begin{array}{c}0 \\
84.4 \%\end{array}$ & $\begin{array}{l}20 \% \\
10 \%\end{array}$ & $\begin{array}{l}0 \\
44.4 \%\end{array}$ & $\begin{array}{l}0 \\
71.4 \%\end{array}$ & $\begin{array}{l}100 \% \\
0\end{array}$ \\
\hline \multicolumn{6}{|l|}{ History of abortions } \\
\hline Yes & $26.5 \%$ & $31.6 \%$ & $33.3 \%$ & $28.6 \%$ & 0 \\
\hline $\begin{array}{l}\text { Mean Age at menarche } \\
\text { in years }\end{array}$ & 12.67 & 12.9 & 11.56 & 12.29 & 13.67 \\
\hline $\begin{array}{l}\text { Mean Age at marriage } \\
\text { in years }\end{array}$ & 14.77 & 16.21 & 14.39 & 15.57 & 17.33 \\
\hline $\begin{array}{l}\text { Mean Age at first child } \\
\text { birth in years }\end{array}$ & 16.28 & 17.8 & 16.56 & 17 & - \\
\hline $\begin{array}{l}\text { Mean Age at } \\
\text { menopause in years }\end{array}$ & 47.44 & 46.00 & 48.31 & 47.50 & - \\
\hline
\end{tabular}

\section{Discussion}

A hospital based descriptive study was conducted to assess the socio demographic profile, reproductive characteristics and the associated risk factors among the gynecological cancer patients attending King George Hospital, Visakhapatnam.

\subsection{Type of cancer and stage of cancer:}

In our study, a total of 183 gynecological cancer cases were included of which cancer cervix $(73.8 \%)$ was the most common malignancy among all the gynecological malignancies followed by cancer ovary $(10.9 \%)$ and cancer uterus $(9.8 \%)$. This finding was in concurrence with a study done by Hemalatha et al $(2012){ }^{[8]}$ where cervical malignancies were the commonest with more than $70 \%$ of the gynecological cancers. Similarly other authors ${ }^{[21,22,23,24]}$ identified cervical malignancy as the commonest among all the gynecological malignancies. Among our study participants most of the patients presented in advanced stages of the disease i.e., 55.2\% in III rd. stage and $27.9 \%$ in $\mathrm{IV}^{\text {th }}$ stage of disease. Reporting late in the advanced stage was high among cancer cervix patients. Similar finding was observed by Sultana et al ${ }^{[13]}$ in their study in Bangladesh where $75 \%$ of thseir patients had advanced disease due to late presentation with $75 \%$ of cancer cervix patients. Also Sarkar et al (2012) ${ }^{[3]}$ observed that $48.7 \%$ of their study population were in the III rd stage of disease at the time of presentation.

Delayed presentation of the cases always results in poor outcome, which could be averted by early detection of these cancers and prompt institution of treatment. Therefore, prevention and early detection of cancer needs more attention

\subsection{Age distribution:}


The age of the study population ranged from 18-80 years. Majority were in the age group of 36-45 years and the mean age of the study population was 48.22 years. The mean age of cervical cancer and ovarian cancer patients was 47.09 years and 47.10 years respectively whereas the mean age of uterine cancer patients was 65.72 years which was two decades above the mean age of the patients with gynecological malignancies. In contrast to that, the mean age of vulvar cancer and GTN patients was found to be 39.86 years and 21 years that lie below the mean age of the patients with gynecological malignancies. This observation was in concurrence with other studies done in different parts of the developing countries. Hemalatha et al (2013) ${ }^{[8]}$ in their study in India, observed that the median age of gynecological cancer patients was 47 years.

A study done by Madhutandra Sarkar (2012) ${ }^{[3]}$ in Kolkata, reported that the mean age of the gynecological cancer patients was 45.8 years with the mean age for cervical cancer 48.1 years, uterine cancer 53 years and ovarian cancer was 43.3 years.

Chhabra et al. (2002) ${ }^{[4]}$ reported that nearly half $(44.6 \%)$ of the gynecological malignancy cases occurred between the ages of 35 and 49 years. The mean age of cervical cancer cases was 45.7 years and $38.3 \%$ of ovarian cancer cases occurred between the ages of 35 and 49 years.

A study done in Ghana (Nkyekyer, 2000) ${ }^{[12]}$ had shown that the largest proportion $(70.0 \%)$ of gynecological cancers occurred in 40-69 years age group. The mean age for cervical carcinoma was 52.0 years while that for ovarian carcinoma 46.4 years and endometrial carcinoma 56.0 years.

All these studies bring out an almost similar picture in terms of age range and the peak age group of patients was in the fourth decade of life. Hence it was observed that age plays an important role in the development of gynecological cancers.

\subsection{Economic status:}

The mean per capita income of the family among the study population, in the present study was Rs.1335.2 which is nearly one fourth of the national average per capita income (Rs. 5,729 per month). Nearly $3 / 4^{\text {th }}$ of the study population belong to either lower or upper lower economic class. Similar finding was seen in a study done by Raja Rao and Hemant (2013) ${ }^{[14]}$ who studied the socio demographic profile of cervical cancer patients in Karimnagar, Andhra Pradesh, where majority (62\%) of the study population were from lower class of socioeconomic status and also by Sultana et al ${ }^{[13]}$ in their study observed that $66 \%$ of cancer cervix patients belong to low socioeconomic group. The low income group may be related to high incidence of early marriage, high parity, low attendance to physician and make this vulnerable for the development of cervical cancer.

Also most of the women with low incomes may not have ready access to adequate health care services which might lead to their late presentation in an appropriate health facility. The observation has been further supported by published report from South -East Asia, Department of Health, Government of Hong Kong Administrative Region, $2004^{[15]}$ and earlier studies by Chhabra et al 2002:; ${ }^{[4]}$ Madhutandra Sarkar et al 2012 ${ }^{[3]}$. Also, Krieger et al $(1999)^{[16]}$ in their study found that incidence of cervical cancer was inversely related to socioeconomic status among various racial/ethnic groups, poor and working class women.

\subsection{Marital status:}

Majority of the study population in the present study were married (63.9\%) and among cervical cancer patients nearly two thirds were married. Only 2 patients among the study population were unmarried of whom one was a cervical cancer patient and one was an ovarian cancer patient. Among 181 ever-married patients with gynecological malignancies, all the patients had an early marriage i.e., they were married before the age of 19 years. The mean age at marriage was 14.96 years in the present study which is far below the national and state average. The average age at marriage among women in India as per DLHS (2007-2008) is 19.2 years. While the average age at marriage in India for women has been rising slowly over the past twenty years, the practice of child marriage is still widespread and young girls suffer most as a result of it. With early and closely timed pregnancies before their bodies are sufficiently mature, the health of mother and child is severely endangered and often permanently damaged. Girls who marry at a very young age are also more vulnerable to domestic violence and sexual abuse. In the study conducted by Sandeep Singh et al (2011) in Gwalior ${ }^{[17]}$ India, it was observed that the percentage of dysplastic smears were found to be high in women who were married below 15 years of age indicating the association between early age at marriage and cervical cancer in women.

Sharma et al.(2005) ${ }^{[18],}$ Sarkar et al(2012) ${ }^{[3]}$, Kidanto et al.(2002) ${ }^{[19],}$ in their studies also supported the fact that early marriage is a predisposing factor for cervical cancers in their studies. This was also supported by the health report from Hong Kong (Department of Health, Government of Hong Kong Administrative Region, $2004)^{[15]}$ which stated that women with sexual intercourse at an early age are at higher risk of cervical cancer than women with sexual experience later in life.

\subsection{Parity}


Multiparity (> 3) was more commonly seen among Cancer Cervix patients (85\%), Cancer Uterus (73\%) and Cancer Vulva patients (71\%) as compared to other gynecological cancers. None of the Ovarian Cancer patients were multiparous and all GTN patients were nulliparous. A relationship has been found between the reproductive characteristics and proportion of patients with cervical cancer and ovarian cancer. The proportion of patients with cancer cervix increased with increasing parity. This observation that most of the patients with gynecological malignancies were multiparous was in concurrence with different studies done in

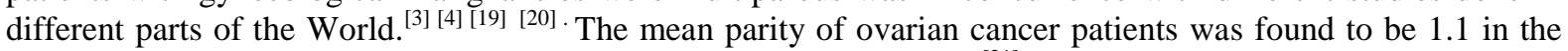
present study. This finding was similar to a study done by Daly et al., ${ }^{[21]}$ in Ireland. In the present study, nearly $40 \%$ of the ovarian cancer patients were nulliparous which corroborates with the medical literature that ovarian malignancy is more common amongst nulliparous ${ }^{[22]}$ However studies from the developing countries indicate that patients with ovarian cancer may also be multiparous alike cervical cancer patients. ${ }^{\left[{ }^{[3]}[4][19]\left[{ }^{[20]}\right.\right.}$

It has been postulated that high parity may increase the risk of cervical cancer by maintaining the transformation zone on the ectocervix for many years facilitating the exposure to HPV and, possibly to other, cofactors. Hormonal changes induced by pregnancy may also modulate the immune response to HPV and influence the risk of persistence or progression ${ }^{[23]}$

\subsection{Age at first child birth:}

In this study, the mean age at first child birth was 16.49 yrs. This observation was similar to the study conducted by Aparajitha Dasgupta et al ${ }^{[24]}$ where $49.5 \%$ of their study population had age at first child birth less than 18 years .Similarly Wilson et al ${ }^{[25]}$ in their study observed that relative risk for first birth at ages $\geqslant 17$ years was significantly lower than relative risk for first birth at age 13 for cervical cancer. Cervical cancer risk among parous women is $77 \%$ higher in those under 17 years old at their first full term pregnancy, compared with those aged 25 years or older, a pooled analysis has shown. The association with age at first child birth is limited to squamous cell carcinoma, with no association for adenocervix, this pooled analysis has shown ${ }^{[26]}$ Similarly, Dutta et al ${ }^{[27]}$ observed in their study, that the relative risk of acquiring the cervical cancer was 6 times more in case of women who had first child before 18 years of age as compared to those who had the first child after the age of 18 years.

Lower age at first child birth was found to be significantly associated with subsequent development of cancer cervix. This may be attributed to early sexual activities, hormonal changes during pregnancy or may be due to cervical trauma during delivery at a relatively younger age of mother.

However, Morgen et al (2001) ${ }^{[28]}$ in their study conducted in Sweden commented that increasing maternal age at first child birth was associated with an increasing risk of endometrial and ovarian cancers, and with a decreased risk of cervical cancer.

\subsection{Menstrual history:}

In the present study $79.2 \%$ of the study population had regular menstrual cycles while $20.8 \%$ had irregular menstrual history associated with polymenorrhoea or abnormal vaginal bleeding during menstruation. In the studies conducted by Madhutandra Sarkar et al (2011) ${ }^{[3]}$ and Chhabra et al (2005) ${ }^{[4]}$, they observed that heavy, prolonged or infrequent menses was one of the common symptom associated with gynecological malignancies with which the women comes to the health center.

In our study, the mean age at menarche was found to be 12.52 years and it was least among uterine cancer patients (11.56 years) as compared to other gynecological cancers. Manjusha Viswanathan et $\mathrm{al}^{[29]}$ in their study stated that early menarche, late menopause are said to be the risk factors for the development of uterine cancer and in their study $23.3 \%$ of women had menarche before 12 years of age.

Menopause also plays a vital role in the development of gynecological malignancies. The reason for this might be prolonged exposure to progesterone deficient cycles in this age group. In India, the mean age at menopause among general population is 47.5 years ${ }^{[30]}$

\subsection{Menstrual hygiene:}

About $67.8 \%$ of the study population with gynecological malignancies in this study used old or reused cloth pieces during associated with the use of unclean cloth was 2.5 fold higher for the development of CIN III (cervical intra-epithelial neoplasia) and malignancy as compared to the use of clean cloth or use of sanitary napkins. Similarly Aparajitha Dasgupta et al (2002) ${ }^{[24]}$ in their study observed that $69 \%$ of the cancer cervix patients had unhygienic genital practices.

\section{Conclusions}

From this study and reported literature, it can be concluded that women in $40^{\text {‘s }}$ were most commonly affected and cervical malignancy has been identified as the most common gynecological malignancy. Majority of these cases were presented in advanced stage of the disease. Hence women should be made aware of not only 
possible warning signs but also the urgency of seeking appropriate health care so that the mortality and morbidity due to gynecological cancers can be reduced.

\section{Recommendations}

1. Cervical cancer is identified as the most common gynecological cancer and is the only gynecological cancer for which a screening test is present and can be cured if diagnosed early. All the women must be motivated to go for screening irrespective of the health status so that the disease could be diagnosed early.

2. Clinic based facilities for screening and regular gynecological examination with effective surveillance system to be made available at all first referral units/CHCs/District hospitals so that mortality and morbidity because of gynecological cancers can be reduced and there is a need for initiation of community screening and educational programs through awareness campaigns.

3. A high proportion of patients presented in stages III (55.2\%) and IV (27.9\%). This emphasizes the need for early detection of Gynecological cancers in our population. Accordingly, the importance of detection of the pre-clinical stage of the diseases by considering the possibility of initiating cost-effective screening measures needs to be emphasized.

4. There are no screening tools with sufficient accuracy to be recommended for use in general population for all other gynecological cancers. Therefore, preventive measures should be given more importance while giving health education.

5. Health education and creating awareness among women regarding the symptoms of gynecological cancers, diagnostic camps, lifestyle education, identification and reduction of risk factors, so that they may seek health care at an early stage of disease must be carried out regularly.

6. A thorough symptomatological screening for gynecological cancers should be done in all women coming for some problem in the hospital so as to detect and treat the malignancies at the earliest and to decrease the incidence of advanced cancer. Even if cancer is not evident, continuation of follow up checking on a regular basis need to be ensured.

\section{References}

[1]. Gupta S, Rao YN, Agarwal SP. Emerging strategies for cancer control for women in India. 50 years of cancer control in India: 2003.Available from http://www.medindia.net/education/ministry of health/pg 192-203.pdf. (Last accessed on June $14^{\text {th }} 2014$.)

[2]. Kishore J. Text book of National Health Programs of India.11 ${ }^{\text {th }}$ edition. New Delhi: Century publications; 2014.

[3]. Madhutandra Sarkar, Hiralal Konar, DK Raut. Gynecological malignancies: Epidemiological characteristics of the patients in a tertiary care hospital in India.Asian Pacific Journal of cancer Prevention 2012; 13: 2997-3004.

[4]. Chhabra S, Sonak M, Prem V, Sharma S.Gynaecological malignancies in a rural institute in India. J Obstet Gynecol India 2002; 58:518-88

[5]. Ayinde OA, Omigbodun AO, Ilesanmi AO. Awareness of Cervical Cancer, Papanicolaou's Smear and Its Utilisation among Female Undergraduates in Ibadan. Afr J Reprod Health 2004; 8: 68-80.

[6]. Consolidated report of hospital based cancer registries 2001-3, national cancer registry program; New Delhi; Indian Council of Medical Research . 2007

[7]. K.Umadevi. Current status of Gynecological cancer care in India, J Gynecol Oncol June 2009; 20(2): 77-80.

[8]. Hemalatha AL, Gayathri MN, Deepthi B Ramesh, Neelima P Chamarthy, Giripunja M, Nayana NS. Evaluation of trends in the profile of gynecologic malignancies at a tertiary care hospital in Karnataka, South India. Int j Med Res Health Sci. 2013; 2(4): 87087

[9]. Nwosu SO, Anya SE. Malignancies of the female genital tract at the University of Port Harcourt Teaching Hospital: a ten year review --1990-1999. Niger Postgrad Med J 2004; 11(2):107-9.

[10]. Kyari O, Nagada H, Mairiga A. Malignant tumours of female Genital tract in North Eastern Nigeria . East Afr Med J 2004; 81(3): $142-5$.

[11]. Urmi Sen, Sankaranarayanan R, Mandal S, Ramanakumar AV, Parkin DM, Siddiqi M. Cancer patterns in eastern India: the first report of the Kolkata cancer registry. Int J Cancer 2002; 100(1):86-91

[12]. K.Nkyekyer. Pattern of gynecological cancers in Ghana East African Medical Journal October 2000; 77:10

[13]. R.Sultana, N.Sultana. Clinical profile and treatment protocol of invasive carcinoma of cervix. Bang Med J (Khulana) 2012; 45:1114.

[14]. Raja Rao P and Hemanth Kumar B. Study of Socio Demographic Profile of Cancer Cervix patients in Tertiary care Hospital, Karimnagar. Int J Biol Med Res 2012; 3(4):2306-2310.

[15]. Surveillance, Epidemiology Branch, Centre for Health Protection, Department of Health, Government of the Hong Kong Special Administrative Region (2004). Topical Health Report No. 4. Prevention and Screening of Cervical Cancer. Hong Kong: Department of Health

[16]. Krieger N, Quesenberry C Jr,Peng T, Horn -Ross P, Stewart S, Brown S, Swallen K, Guillermo T, Suh D, Alvarez- Martinez L, Ward F.Social class, race/ethinicity, and incidence of breast, cervix,colon,lung and prostate cancer among Asian, Black, Hispanic and White residents of the San Francisco Bay Area,1988-92(United States). Cancer Causes Control, 1999 Dec;10(6):525-37

[17]. Singh S, Badaya S. An Epidemiological study of various Risk factors for Carcinoma Cervix: A Study from a Tertiary Care Hospital in Gwalior, India. WebMedcentral CANCER 2012; 3(4): WMC003315.

[18]. Sharma R, Maheshwari V, Aftab M, Das BC . Role of different epidemiological factors, colposcopy and cytology in the screening of cervical cancer in symptomatic patients. Indian J Med Res 2005; 121:109-10.

[19]. Kidanto HL, Kilewo CD, Moshiro C. Cancer of the cervix: knowledge and attitudes of female patients admitted at Muhimbili National Hospital, Dar es Salaam. East Afr Med J, 2002; 79: 467-75

[20]. Wilson HG, Curtis PA, Marchbanks. Parity, age at first birth and risk of invasive cervical cancer, A meta- analysis report. Centers for Disease Control and Prevention, Atlanta, GA USA. 
[21]. Daly C, Fitzpatrick R, Murphy H. Ovarian cancer in a county hospital. Ir Med J,1989 ; 82: 60-1.

[22]. Dutta DC . Text Book of Gynaecology including contraception, Fourth Edition. Calcutta: New Central Book Agency (P) Ltd,2003

[23]. Dutta DC . Text Book of Gynaecology including contraception, Fourth Edition. Calcutta: New Central Book Agency (P) Ltd,2003.

[24]. Aparajitha Dasgupta, Narendra N, Naskar, Rama Ram, Sila Deb. A community based study on the prevalence of risk factors of cancer cervix in married women of a rural area in West Bengal. Ind J of Community Med 2002 Jan-March;27(1):35-38.

[25]. International collaboration of Epidemiological studies of Cervical cancer-Cevical Carcinoma and Reproductive factors: collaborative reanalysis of individual data on 16,563 women with cervical carcinoma and 33,542 women without cervical carcinoma from 25 epidemiologicalstudies. Int J Cancer ,2006;119(5):1108-24

[26]. Dutta PK et al: A case -control study of cancer cervix patients attending command hospital ,Pune. Ind J Cancer,1990; 27:101-6

[27]. Mogren I, Stenlund H, Hogberg U. Long-term impact of reproductive factors on the risk of cervical, endometrial, ovarian and breast cancer. Acta Oncol,2001; 40: 849-54

[28]. Jyothi Unni, Third consensus meeting of the Indian menopause society-.A Summary,2008; J Midlife Health, 2010 Jan-Jun; 1 (1):4347

[29]. Manjusha Viswanathan, Suja Daniel, Shailaja M, Nazeema A.Socio-demographic Profile of Patients with Postmenopausal Bleeding attending Out-Patient Unit of a Tertiary Care Center,Sch.J.App.Med.Sci.,2014;2(2C):681-684

[30]. Aditi Kishore Shinde,M.S, Soumyabrata Munshi,,Subhash Chandra Biswas, Avijit Hazra,Sasanka Chakrabarthi, Association of Life style Risk factors in Common Gynecological Cancers.Int J Biol Med Res , 2014; 5(3):4239-4299 